conspicuous faults. We have exerted a continuously beneficial influence upon the conduct of the final examinations in medicine, surgery, and midwifery, and we have, I think, held a steady balance between counsels of perfection and practical possibilities. We have to a great extent stopped the improper employment of unqualified assistants. In a word, I think we have "done our duty," and not least in aroiding courses which were sometimes tempting, but which, if we had pursued them, would have brought us into collision with public opinion, if not with the Privy Council and with Parliament. We are indebted to our excellent legal advisers for the fact that, although many of our decisions have been questioned, all of them without exception have been affirmed by the highest tribunals.

This letter is already far too long, but I must petition for a few lines more. I am as conscious as any of our critics that the medical profession has many and reasonable causes of complaint, and $I$ am not surprised at the half articulate cry against the Council, although I altogether deny its justice. In my humble opinion the redress of our grievances, whatever they are, will only be obtained by educating the public; and this we have neither done nor tried to do. About thirty years ago I submitted to the British Medical Association a proposal to abandon its journal and to replace it by a high-class monthly or quarterly review, edited by a man of distinguished professional position and containing unsigned articles, full, lucid, temperate, by scholarly and capable writers, addressed to the public from the profession, and setting forth the professional view on all the numerous subjects, social or on the borderland of medicine, upon which medical men are able to speak with special and peculiar knowledge. If such a journal had been commenced and well conducted I feel sure that, even long ago, it would hase been possible for us to go to Parliament and to ask successfully for powers and privileges which would now be refused to us, and refused in the interests and for the protection of the quacks and "antis" whom we have never taken any proper measures to expose. Moreover, if we are to do any good we must organise ourselves as well as educate others, and we must take care that our organisation is controlled by the leaders of thought among us, and not by people who seek in notoriety their only hope of escape from insignificance. I for one should be glad if every medical man in practice, like every solicitor, were compelled to take out his yearly certificate, and if the money thus accruing could be applied to the promotion of the corporate objects of the profession. Such a change may come in time. In the meanwhile, I would appeal to the practitioners of England to send to the Council men who will be representative of the best knowledge and of the highest aims of their brethren, and who are qualified by education, by experience, and by professional and social position to hold their own among the colleagues in whose deliberations they will take part.

I am, Sirs, yours faithfully,

Harley-street, Aug. 1st, $1896 . \quad$ R. BRUdentel CART'Rr.

\section{"THE PRESIDENCY OF THE ROYAL COLLEGE OF SURGEONS OF ENGLAND."}

\section{To the Editors of THE LANCET.}

SiRS,-Y Your article on the Presidency of the Royal College of Surgeons of England in THe LANCEI of July 25th contained part of the truth, and probably one or two votes may have been influenced by the considerations you have referred to. In order to complete the matter I enclose for publication a statement which $I$ read to the Council at its meeting this afternoon.

I am, Sirs, yours obediently,

Cavendish-square, W., Aug. 4th, 1896. ChRIstopher Heit'H.

Statement Enclosed.

"Before the minutes are confirmed I wish to say a few words of personal explanation. I understand that, immediately before the last meeting of this Council, two of its members were busily canvassing against my re-election as President on the ground that I had degraded my office by accepting an invitation to give in America a course of lectures to which an honorarium was attached. It will, I fancy, very much surprise our American friends when they learn that exception has been taken to this; and I may say that among those whom I consulted before I accepted the offer was our President, who strongly urged me to do so.
As regards the honorarium, to which I am told special exception has been made, I should like to point out that every lectureship in this College has an honorarium attached to it and that the amount of that attached to the American lectureship is not more than sufficient to cover the expenses of the long journey. But the point I want to make quite clear to the Council, and which must have been known to my censors, is this: that my engagement is for next yearfor September, 1897-and could, therefore, have no relation whatever to the election for the present year."

\section{"THE CAUSE OF MALARIA." To the Editors of THE LANCET.}

SIRS,-Referring to Surgeon-Lieutenant Payne's letter in your issue of the 1st inst., describing the fusion of the spherules of a Laveran's rosette body, I would suggest that this phenomenon-by no means an unusual one-is not a vital, but a mechanical one ; that it is owing to crushing of the delicate parasite by the gradually increasing pressure brought about by the progressive thinning of the layer of blood from evaporation at the edge of the cover-glass. The plasmodium in this way is killed and crushed, and becoming somewhat diffluent the elements composing it run together by molecular attraction. If, however, this fusion of the spherules of the rosette be a vital process the body exhibiting it, as Surgeon-Lieutenant Payne remarks, cannot be a parasite, but for the same reason neither can it be a white blood corpuscle, as Surgeon-Lieutenant-Colonel Lawrie would have us believe.

I would ask Surgeon-Lieutenant Payne how he assured himself that the spherules were non-nucleated.

Aug. 3rd, 1896 I am, Sirs, yours truly, Patrick Manson.

\section{"A CASE OF F ACAL FISTULA: A NEW MODIFICATION OF ENTERECTOMY." \\ To the Editors of THE LANCET.}

SrRs,-Whilst I would attach every weight to Mr. Jessett's statement in THE LANCET of Aug. 1st that ample securit against fæcal extravasation can be obtained by simply packing with wool or gauze the open fistula, still, I think that the method I learned from Dr. Oswin is safer, and this safety can be procured without any very elaborate mancurres. In answer to his query as to the method of suturing the intestine, as I had plenty of room I simply sutured end to end without any bone plate. So far as I have seen, Murphy's button and such like contrivances are only needful where from some reason the intestine cannot be freely and easily handled, or where from exhaustion time has become an important feature in the case.

Leeds, August 4th, 1896.

I am, Sirs, yours faithfully,

\section{"TRAVELLING ABROAD FOR HEALTH AND PLEASURE." \\ To the Editors of THE LANCET.}

SIRS,- - The leading articles upon the above subject which appeared in THE LANCET of July 18th and 25th are ver opportune and will be perused with interest and profit by many readers. Your insistence upon the necessity of avoiding worry or over-exertion in connexion with summer holidays is most important at this season, and there is much truth in what you say about financial considerations, bad sanitation, and overcrowding being fruitful sources of worr and anxiety which too frequently prevent any benefit that otherwise might be expected. Whilst you have much to sa? in favour of Continental travelling you very properly recognise the many inconveniences of holidays spent on the Continent I am, however, compelled to disagree with you slightly upon the subject of the comparative cost of residence at British and Continental health resorts. You say that it is infinitel cheaper to visit the latter, and instance certain hotels in Switzerland, South of France, Spain, and Italy wher excellent board and lodging can be obtained at from 4s. to 7s. per day. That this is scarcely a fair comparison is proved by your admission that " English drainage and Englisb cleanliness are accompanied by the exorbitant charges of English hotels" at many Continental resorts. But, Sirs, can 
the English charges be fairly styled exorbitant? I think not, unless you ignore the fact that " English drainage and English cleanliness" are not only sanitary necessities, but of the nature of costly luxuries, which have to be paid for somehow. I think it will be allowed that the cost of these luxuries is pretty much the same whether obtained at an English or a Continental health resort. That these advantages are superior and more amply provided at British spas and watering-places is now generally admitted by the profession, and is one of the strongest motives which induce many thousands to choose our home resorts in preference to foreign resorts. There is another aspect of this question which I should like to bring before your readers. It is this, that the crowding of a vast majority of visitors and invalids into one short holiday season which lasts only some six or eight weeks during two months (August and September) is not only responsible for those bigh charges and the financial worry to many visitors which you rightly deplore, but also too often for the overcrowding of sleeping accommodation, bad cooking, inferior attendance, and numerous other objectionable features of the great English holiday season. Now much of this could be prevented if visitors and invalids able to do so would only choose more frequently the months of spring, early summer, and late autumn for their holidays. In these months hotels and lodging-houses can, and indeed do, provide better accommodation at greatly reduced cost, which in many cases comes to half that of August and September.

I am well aware that there are many who, either from business or social exigencies, are prevented from taking their holidays at any time except in the two months mentioned. On the other hand, there are large numbers who are unfettered in this respect.

The advantages of the course suggested are so great, particularly to invalids, that I cannot too strongly urge upon medical men the desirability of advising their patients when practicable to take their holidays either before or after the crowded part of the summer season. I would even go further and point out the frequent advantage of advising two shorter holidays in lieu of a single longer one. The habit of visiting some health resort or other for two or three weeks, first in April, May, or June, and again for a similar period in October or the latter part of September, is growing in favour, and possesses not only the advantages of better and cheaper accommodation, but provides two changes in place of one annually and reduces the interval between the holidays from nearly a year to half that period.

I remain, Sirs, yours faithfully,

SAMUEL HYDE, M.D. St. And.

Chairman of Council, British Balneological and

July 25th, 1896. Chairman of Council, British Balnelogical Society.

\section{"THY IS THE LEFT HEART STRONGER THAN THE RIGHT?" \\ To the Editors of THE LANCET.}

SIRS,-All Dr. Harry Campbell's writings bear the evidence of personal thought and the conclusions at which he arrives are the logical consequence of his premisses. In making a few remarks upon his query, "Why is the left heart stronger than the right?" I do so in a spirit of courtesy to the writer, but with a sense of bewilderment with regard to his conception of the physics of the circulation. My bewilderment is possibly a measure of $m y$ ignorance and $I$ am anxious and ready to be rightly informed. Like many others I have hitherto been under the impression that muscular development or power bore a direct relation to the resistance to be overcome, and that inasmuch as pressure decreases and inertia increases with the length of a conduit for fluid, so the force necessary to overcome this increasing inertia must rolatively increase also. This elementary fact is, of course, capable of experimental proof. When to this we add the oscillating character of wave-like movement in the circulation-of which we know very little at present-and the greater blood-weight in the systemic vessels we certainly hare, I would suggest, conditions quite capable of explaining the greater force necessary to drive the systemic circulation without importing the physiological factor of vaso-motor regulation of that system. The constant modification of the blood-supply to various parts of the body to which Dr. Campbell refers is associated with local compensatory relief-that is, a rise of pressure in one quarter is balanced by a fall of pressure in another. It, therefore, appears to me that the paradoxical conclusion arrived at by Dr. Campbell is untenable. The anatomical differt nces between the systemic and pulmonar $y$ circuits and the difference in the weight of their contents respectively appear to me a sufficient explanation of the difference between the power of the right and left ventricle. That the expedients devised by nature for effecting one purpose frequently serve also another is incontrovertible. The fact, therefore, that the systemic vessels contain more blood than the pulmonary and have a development and innervation which enable them to modify the blood-supply to different parts, no more raises the latter physiological factor to the first rank as a cause of the vascular difference in question than does the fact that the thin-walled vessels of the pulmonary system admitting of easy aeration of the blood constitutes the latter function the cause of the easier transit of blood through that circuit. There are other portions of Dr. Campbell's communication which are neither clear nor convincing, but which it would occupy too much of your valuable space to comment upon at length. Thus he says: "Every time a ventricleful of blood passes through the larger segment it [the italics are mine] has to traverse the smaller one." It cannot be that Dr. Campbell means that the same ventricleful of blood does so, but this is the sense conveyed to my mind by the passage I have quoted. A factor which Dr. Campbell has not taken into account, but one which cannot be ignored, is the influence upon both the pulmonic and systemic, but especially pulmonic, circulation of thoracic aspiration. It cannot well be denied that the aid afforded to the dextrocardial circulation by the action of the thorax is one of the causes of the less powerful development of the right as compared with the left ventricle. Thus, Sirs, as I am compelled. to reject Dr. Campbell's premisses as fallacious, I am unable to accept the truly "remarkable conclusion" at which he arrives in his paper.- I am, Sirs, yours faithfully, AleXANDER MoRIson, M.D. Edin.

Upper Berkeley-street, W., July 27th, 1896.

\section{THE NOMENCLATURE OF DISEASES. To the Editors of THE LANCET.}

Sirs,-A copy of the third edition of the Nomenclature of Diseases has reached me this morning, which one naturally expected to find well-nigh perfect. On turning, however, to page 7, where are recorded "General Diseases," in which I am not only interested but deeply concerned, it is difficult to imagine the condition of mind which has impelled the august members of the joint committee, in the midst of the English names of our common diseases, such as small-pox, chicken-pox, measles, scarlet fever, and mumps, to suddenly insert the name " rubella," and expect it to be used in everyday life. The committee might just as well expect to supplant the name of "whooping-cough" by " vertussis." We are, therefore, still to have, for another ten years, two distinct and definite diseases, and the one not affording protection from the other, called by the same name "measles," for in daily life the word "German" is omitted, at least such is the case in the majority of certificates which come into my hands from all parts of the country and which consequently entail endless trouble and anxiety to find out which measles has occurred.

It seems inconceivable that the committee in the case of scarlet fever should enter it thus : "Scarlet fever, synonym scarlatina," while in roserash, as also in dengue, it is reversed-"Rubella, synonym German measles," "Dengue, synonym breakbone fever." It is evident that the joint committee has been caught napping, or perhaps rubella was "made in Germany."-I am, Sirs, your obedient servant, Rugby, July 29th, 1896. CLEMENT DUKES, M.D. Lond.

\section{"THE MILDER VARIETIES OF APPENDICITIS." \\ To the Editors of THE LANCET.}

SIRs,-I bave not seen it mentioned anywhere that a decubitus, other than the ordinary dorsal one, is of great advantage in arriving at a correct physical examination of the abdomen in some cases of appendicitis. I have derived very great assistance by placing the patient on his or her left side with the shoulders low and the legs drawn up. By this decubitus, especially in a parous woman, it is much more 